\title{
ORGANIZADORES PRÉVIOS PARA APRENDIZAGEM SIGNIFICATIVA EM FÍSICA: O FORMATO CURTA DE ANIMAC̣ÃO
}

\author{
Rafael João Ribeiro* \\ Sani de Carvalho Rutz da Silva** \\ André Koscianski***
}

RESUMO: A teoria da aprendizagem significativa enfatiza a importância da ancoragem seletiva entre ideias já existentes e as ideias novas no processo de aquisição de conhecimentos. A eficiência desse processo depende, entre outros fatores, da presença de subsunçores. $\mathrm{Na}$ falta deles, pode-se incluir organizadores prévios, mecanismos didáticos que auxiliam a preparação de ideias âncora. Esta pesquisa investigou a construção de um organizador prévio no formato de curta de animação digital, discutindo os critérios didáticos e técnicos envolvidos nessa tarefa. Um curta foi criado e aplicado em uma aula de Física, se mostrando efetivo na função de organizador prévio. O trabalho enumera características que orientam a construção de um curta de animação com função de organizador prévio.

Palavras-chave: Aprendizagem Significativa; Organizador Prévio; Curta de Animação.

\section{ADVANCE ORGANIZERS FOR MEANINGFUL LEARNING IN PHYSICS: THE ANIMATED SHORT FILM FORMAT}

ABSTRACT: Meaningful Learning Theory stresses the importance of the link between existing ideas and new information, during the knowledge acquisition process. The efficiency of this process depends, among other factors, on the presence of subsumers. In the absence of these elements, previous organizers may be employed. They are learning resources that help to prepare anchoring ideas. This research investigates the implementation of an advance organizer in the form of a short-length digital animation. We discuss the educational and technical criteria involved in this task. An animation was created for a Physics class and proved to be effective in the role of advance organizer. The paper enumerates guidelines to create a short animation with the function of advance organizer.

Keywords: Meaningful Learning; Advance Organizer; Animated Short Film. *Mestre em Ensino de Ciência
e Tecnologia, Universidade
Tecnológica Federal do Paraná
(UTFPR). Professor do Instituto
Federal do Paraná - IFPR.
Email: rafaeluepg@hotmail.com
** Doutora em Ciência dos
Materiais pela Universidade
Federal do Rio Grande do Sul
(UFRGS), 2003. Professor
da Universidade Tecnológica
Federal do Paraná (UFTPR).
Email: sanirutz@gmai.com
*** Doutor em Simulação -
Institut National Des Sciences
Appliquées de Rouen (2004).
Professor da Universidade
Tecnológica Federal do
Paraná(UFTPR).
Email: koscianski@utfpr.edu.br 


\section{INTRODUCุÃO}

Em 1963 David Ausubel escreveu Psicologia da Aprendizagem Verbal Significativa $^{1}$, que mais tarde se tornou um livro clássico na área de Educação e uma alternativa para os educadores da época, insatisfeitos com as teorias de aprendizagem por descoberta.

Em sua obra, Ausubel apresenta a teoria cognitiva de aprendizagem significativa por recepção, em oposição a uma aprendizagem por memorização. A palavra "receptiva" é usada por ele para indicar que os conteúdos a serem aprendidos são estabelecidos pelo professor, em contraste com a aprendizagem por descoberta. A ideia de recepção não significa que exista uma atitude passiva dos alunos ou que o processo seja menos eficiente; ao contrário, esse tipo de aprendizagem pode ocupar menos tempo do aluno e ser mais tecnicamente organizado (OLIVEIRA, 1975).

Ausubel partiu da premissa de que a aquisição e retenção de conhecimento resultam de um processo ativo, integrador e interativo entre o material de instrução e as ideias relevantes da estrutura cognitiva do aprendiz. Para um conteúdo "adquirir significado" é importante que haja a associação da nova informação com um conjunto de conhecimentos previamente existentes na estrutura cognitiva do indivíduo (AUSUBEL, 2003).

Dentro da teoria da aprendizagem significativa, o conceito de "subsunçor" se refere a uma ideia já presente na estrutura cognitiva do aprendiz, responsável por fazer a interação ou ponte cognitiva daquilo que já sabe com a nova informação. É através do subsunçor preexistente que o aprendiz poderá fazer uma âncora com a nova informação, promovendo, desta forma, uma aprendizagem significativa, menos mecânica e com mais sentido.

Em um primeiro momento, a ausência de subsunçores impede ou inibe o processo de aprendizagem significativa. Entretanto, nesse caso Ausubel propõe o uso de organizadores prévios: materiais introdutórios que antecedem os conteúdos a serem aprendidos, tratando-os de maneira genérica. Os organizadores prévios ajudam a aprendizagem significativa por salientarem aos alunos informações com as quais já tenham familiaridade e que servirão como substrato para a assimilação do material novo.

No caso do ensino de Física, existe uma dificuldade com conceitos abstratos ou pouco intuitivos, como é o caso de modelos matemáticos de diversos fenômenos. Muitos conteúdos envolvem também processos dinâmicos que são ilustrados e discutidos por meio de representações estáticas, como figuras e digramas em livros e no quadro. Essas representações podem trazer dois problemas aos alunos. Primeiro, elas exigem um esforço de abstração e a capacidade de manter o foco de atenção em algo não palpável. Em segundo lugar, há, em geral, uma dificuldade dos estudantes para fazer a relação entre, por exemplo, um termo de uma equação e um elemento concreto de um fenômeno físico. Isso pode levar a consequências como uma compreensão superficial do conteúdo e alunos que não conseguem generalizar além de situações discutidas em sala. 
Muitos professores buscam enriquecer a aula e contornar os problemas usando maquetes ou, quando possível, equipamentos em laboratório. Um recurso bastante flexível vem das Tecnologias de Comunicação e Informação, na forma de simuladores e vídeos que ilustram situações concretas. Além de favorecer a atenção dos alunos e ser um motivador potencial, os vídeos também constituem um meio privilegiado para representação de conteúdos por permitirem mesclar imagens reais, desenhos, gráficos e textos.

Neste trabalho, estabeleceu-se a hipótese de que um curta de animação teria função de organizador prévio se envolvesse um determinado conceito ou princípio a ser estudado e o apresentasse de maneira significativa para o aprendiz. A palavra "significativa" é empregada aqui para se referir a um processo de ancoragem seletiva, não arbitrário e não literal, dependente da disponibilidade de subsunçores relevantes.

$\mathrm{O}$ artigo discute aspectos da teoria de aprendizagem significativa, tendo em vista a construção de um curta de animação para auxiliar a aprendizagem de um conceito da Física: o "Momento de uma Força". A escolha da função de organizador prévio leva ao fato de que o conteúdo a ser ensinado não é tratado explicitamente. Isso traz uma vantagem adicional que é a total flexibilidade ao professor para abordar a matéria da maneira que for mais apropriada.

Neste trabalho, um vídeo foi inteiramente produzido de forma digital, usando apenas softwares livres. A aplicação em sala de aula, os resultados e impressões dos alunos são também discutidos no texto. Finalmente, é traçado um paralelo entre as características de organizadores prévios e curtas de animação de propósito didático.

\section{METODOLOGIA}

O objetivo geral deste trabalho foi a construção do curta de animação com a função de organizador prévio, tratando o conteúdo "Momento de uma Força", que é pertinente à disciplina de Física do Ensino Médio. O vídeo deveria promover a disponibilidade cognitiva dos alunos e a ancoragem seletiva de ideias, sendo um instrumento viável para realizar essas funções e equivalente a outras mídias possíveis (MULLER, 2008). A pesquisa contou com a aplicação em sala de aula em uma turma do terceiro ano do Ensino Médio, na cidade de Arapoti, no Paraná. Os trinta e oito alunos participantes tinham uma média de idade de 16 anos.

A escolha do formato vídeo implicou determinar as características relevantes, didáticas e técnicas para esse tipo de material didático. O projeto foi organizado em dois eixos principais: planejamento do método de ensino e planejamento da produção do curta. Em síntese, pesquisaram-se as etapas necessárias para concepção, produção e aplicação em sala de aula de um curta de animação com a função de organizador prévio.

O ponto de partida para a construção de um roteiro de vídeo é a escolha do gênero a ser empregado, entre opções como documentário, comédia 
ou suspense (MILLERSON, 2001). A partir dos objetivos do trabalho, durante a etapa de pré-produção selecionou-se uma estrutura clássica formada por três atos (COMPARATO 1983) para o roteiro: I ato: exposição do problema; II ato: complicação do problema; III ato: resolução. Procurando garantir o envolvimento dos alunos, optou-se por um argumento leve e que trouxesse algum humor. Para cumprir a função de organizador prévio, o roteiro deve ser capaz de preparar os aprendizes com ideias âncora, necessárias para assimilação do conteúdo principal que seria posteriormente apresentado. Essas ideias âncora (subsunçores) devem ser manifestadas pelos próprios alunos, e para resolver o aspecto da concepção do curta, foram empregadas estruturas cognitivas hipotéticas.

A escolha de ferramentas de criação e edição digital foi realizada com base na experiência da equipe. Cogitou-se, no início dos trabalhos, a participação de um desenhista profissional, porém, os primeiros ensaios e esboços feitos por um dos autores, já usando os softwares selecionados, mostraram qualidades estéticas julgadas plenamente adequadas pelo grupo de pesquisa. $\mathrm{O}$ aspecto artístico do trabalho foi sempre ponderado com cuidado, por ser considerado muito importante para um envolvimento afetivo positivo dos alunos com o material.

O resultado final do processo de criação do vídeo é um arquivo digital, contendo os quadros de animação codificados. A produção de cada quadro de animação no computador é denominada renderização e pode ser bastante demorada. Neste trabalho, a renderização foi realizada usando uma rede de computadores.

No planejamento da aula, utilizou-se a abordagem descrita por Joyce e Weil (1996). Ela pode ser aplicada com materiais diferentes de vídeos, como textos e imagens, empregados com a função de organizadores prévios. A distribuição de horários da escola limitou a aula de aplicação a 45 minutos; isso levou os pesquisadores a restringir a duração do curta dentro da aula, estabelecendo-se um tempo máximo de 5 minutos, prevendo um tempo de preparação e outro lapso ao final da projeção para manifestações da turma.

Foram utilizados pré-testes e pós-testes, além do registro de comentários dos alunos participantes. Esse material forneceu indicações que contribuíram com conclusões do trabalho. Os testes foram baseados no material desenvolvido por Costa (1989), que aborda o conceito de momento de uma força.

\section{FUNDAMENTAÇÃO TEÓRICA}

\subsection{Aprendizagem significativa}

A aprendizagem significativa é parte de um processo de assimilação que pode ser dividido em fases explicadas pela teoria da assimilação, de Ausubel (2003). Pode-se sintetizar essas fases do seguinte modo: (1) ancoragem seletiva do material de aprendizagem com as ideias na estrutura cognitiva; (2) construção do produto interativo, resultante da combinação das ideias recém-introduzidas com as ideias relevantes existentes; (3) assimilação obliterante, em que a ideia nova e as inicialmente 
existentes tornam-se progressivamente indissociáveis; (4) surgimento de novos significados, subsunçores modificados passíveis de retenção ou esquecimento.

$\mathrm{Na}$ falta de subsunçores, sugere-se o uso de organizadores prévios, que são mecanismos pedagógicos auxiliadores na ligação entre aquilo que o aprendiz já sabe e aquilo que irá adquirir. A justificativa para o uso dos organizadores prévios vem do fato de que as ideias existentes na estrutura cognitiva do aprendiz podem não ter a relevância e o conteúdo suficientes para estabelecerem ligações com as novas ideias introduzidas pelo material de instrução. Nesse caso, o organizador prévio faz o papel de mediador e também faz a alteração das ideias preexistentes, preparando-as para o estudo do material posterior: "apresentam-se os organizadores a um nível mais elevado de abstração, generalidade e inclusão do que os novos materiais a serem aprendidos" (AUSUBEL, 2003, p. 11). Para isso, os organizadores prévios devem salientar os pontos mais evidentes do material e omitir informações menos importantes; eles auxiliam o estudante a realizar sua própria codificação da nova informação na memória (GAZDA, R., FLEMISTER, 1998). A Figura 1 representa a função dos organizadores prévios na aprendizagem significativa.

Figura 1: Representação do organizador prévio como facilitador da ancoragem seletiva.

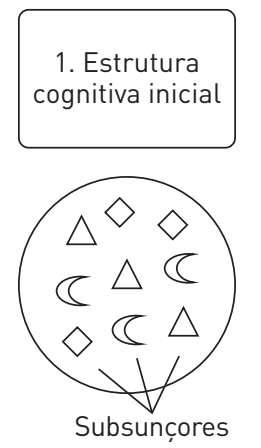

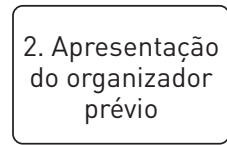
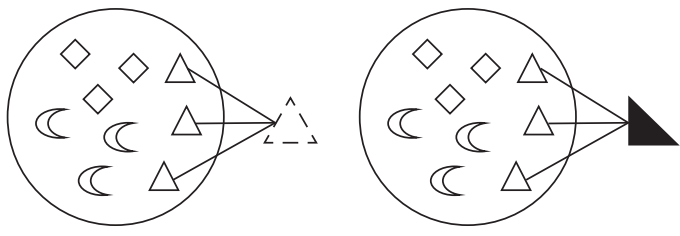

4. Assimilação obliterante e ancoragem seletiva

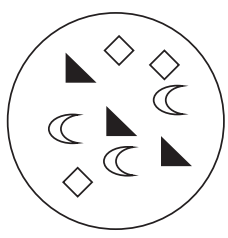

A ancoragem seletiva funciona como uma associação entre alguns dos conhecimentos preexistentes e o material novo. O organizador prévio não antecipa conteúdos novos, mas facilita tecer relacionamentos lógicos entre eles e a estrutura cognitiva existente. É relevante comentar que os organizadores prévios não facilitam a aprendizagem de informações 'sem significado' (NOVAK, 1981).

Os organizadores prévios podem ser divididos de acordo com a forma de aplicação. Quando apresentados antes do material principal de aprendizagem, são definidos como pré-organizadores, que são uniformemente mais eficazes do que os pós-organizadores (MAYER e BROMBAGE, 1978 apud AUSUBEL, 2003). Também podem ser divididos em expositivos e comparativos. Os expositivos são usados com conteúdos novos, relativamente desconhecidos, de forma a fornecer subsunçores relevantes. No caso de material de aprendizagem relativamente familiar, podem ser empregados organizadores prévios comparativos, que auxiliam na discriminação entre as ideias novas e as existentes (AUSUBEL, 2003). Uma 
terceira categoria possível são os pseudo-organizadores, elaborados para facilitar a aprendizagem de tópicos múltiplos e heterogêneos (FARIA, 1989).

Embora seja comum o uso de organizadores prévios na forma de texto, eles podem aparecer também como gravuras, mapas conceituais, filmes, debates, dramatizações e demonstrações em geral (MOREIRA, 2006).

\subsection{Estruturas cognitivas hipotéticas}

Um organizador prévio prepara o terreno para a chegada de novas informações, ativando memórias, destacando conceitos e conhecimentos prévios que o aluno tenha e que poderão ser usados para ancorar as novas informações. Assim, para iniciar a concepção do vídeo, foram elencadas estruturas cognitivas hipotéticas buscando prever as ideias relevantes já disponíveis. Essas estruturas servem de guia para o professor no papel de diretor do processo de ensino-aprendizagem. Três exemplos são ilustrados na Figura 2 a seguir² .

Figura 2: Exemplos de estruturas cognitivas para assimilação de conceitos.

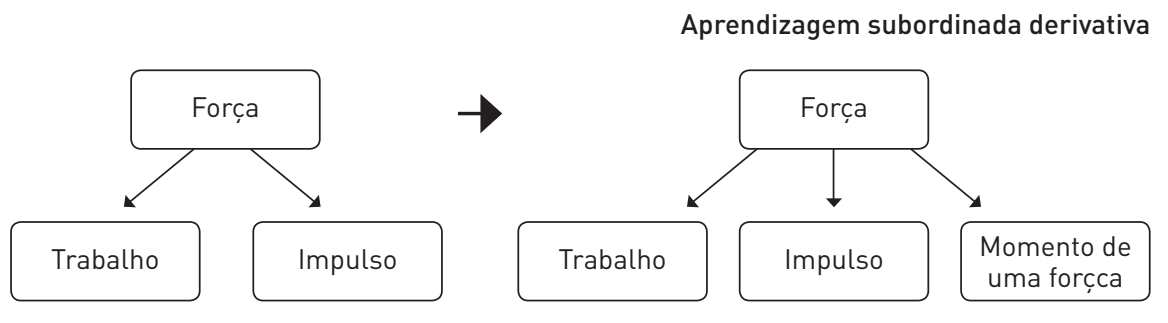

Aprendizagem subordinante
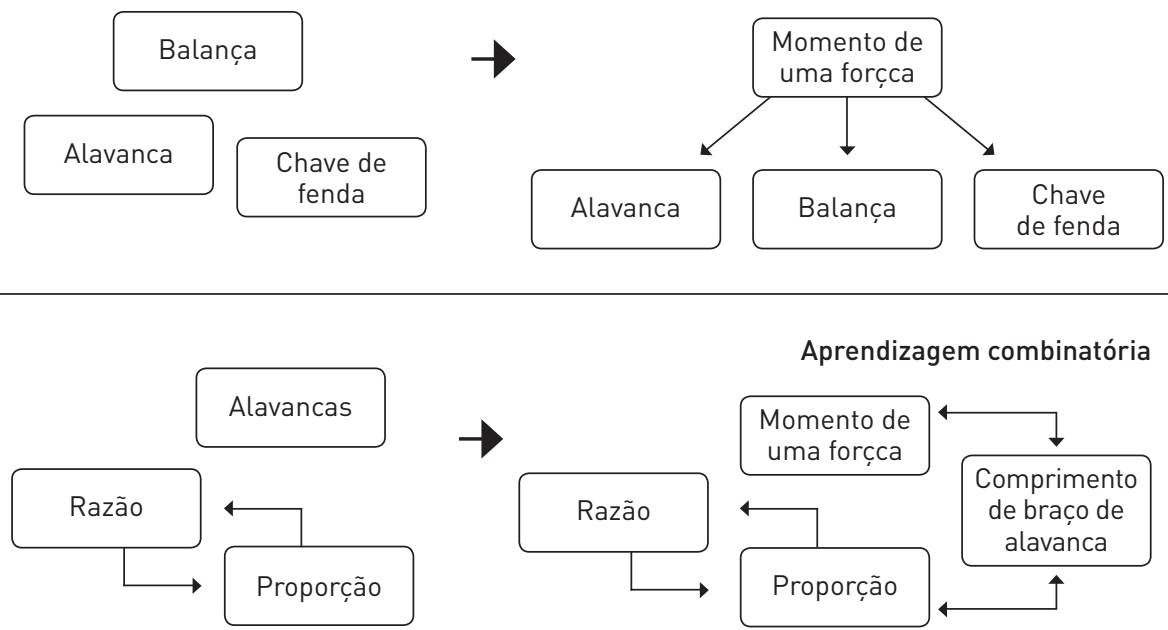

Aprendizagem combinatória

Os três tipos de estruturas ilustrados são:

(1) Aprendizagem subordinada derivativa: a ideia nova (momento de uma força) é 
ligada a uma ideia subordinante já existente (força) e representa um exemplo ou extensão desta. A ideia estabelecida não é modificada.

(2) Aprendizagem subordinante: as ideias já estabelecidas, como exemplos de alavancas, são reconhecidas como casos mais específicos da nova ideia de momento de uma força. Essas ideias antigas transformam-se em ramificações hierarquicamente inferiores da ideia nova.

(3) Aprendizagem combinatória: a ideia nova é relacionada com uma ou mais ideias estabelecidas por analogia ${ }^{3}$, devendo existir alguns atributos em comum entre ambas. Por exemplo, a ideia já existente de "razão e proporção" pode auxiliar a compreensão da relação entre força e distância na construção da grandeza momento de uma força.

\subsection{Abordagem em sala}

Para estruturar uma aula que empregue o vídeo, tomou-se como referência o Método Organizador Prévio sugerido por Joyce e Weil (1996). Esse modelo é composto por quatro fases, sumarizadas na Tabela 1.

Tabela 1: Fases do Método Organizador Prévio de Joyce e Weil (1996).

\begin{tabular}{|l|l|}
\hline \multicolumn{2}{|l|}{ Método Organizador Prévio } \\
\hline Fase I & apresentar o organizador prévio \\
\hline Fase II & apresentar o material principal de aprendizagem \\
\hline Fase III & $\begin{array}{l}\text { fazer a ligação das ideias presentes no organizador prévio com as ideias do material } \\
\text { de aprendizagem }\end{array}$ \\
\hline Fase IV & aplicar a nova aprendizagem em uma tarefa \\
\hline
\end{tabular}

No presente trabalho, a aula pode ser descrita desta forma:

- na Fase I o professor aplica um pré-teste de conhecimentos e apresenta o curta de animação. Em seguida, promove a participação dos alunos, com comentários e indagações sobre o que entenderam do vídeo. A aula prossegue depois que o professor identifica subsunçores no diálogo com os alunos;

- na Fase II, o material principal de aprendizagem é apresentado com informações do livro didático habitual dos alunos e exposição de ideias no quadro de giz. Cabe explicar que seguir rigorosamente o livro didático era uma imposição da escola;

- na Fase III o professor intervém para ajudar os alunos a construir significados. Para isso, foram elaborados slides buscando a ancoragem do conceito apresentado na fase II com as cenas mais importantes da animação apresentada na fase I;

- na Fase IV é realizado um teste de verificação de aprendizagem. Nesta pesquisa, foi usado um pós-teste com o propósito de gerar dados de comparação com o pré-teste. Foram usadas questões adaptadas da pesquisa de Costa (1989). 


\section{PRODUÇÃO DO CURTA DE ANIMAC̣ÃO}

Os processos de planejamento e construção de um vídeo didático podem ser divididos em três tipos de atividades (FERRÉS 1996 p. 92): básicas; complementares e organizacionais. A Tabela 2 lista esses processos.

Tabela 2: Tarefas na produção de um vídeo (Ferrés, 1996, p. 92).

\begin{tabular}{|l|l|l|}
\hline Atividades Básicas & Atividades Complementares & Atividades Organizacionais \\
\hline Delimitação do projeto & Busca de documentação & Previsão de necessidades \\
\hline Sinopse & Fichas de conteúdo & Possibilidades e limitações \\
\hline Roteiro literário & Notas & Plano de realização \\
\hline Roteiro técnico & Observações & \\
\hline Realização & Apontamentos & \\
\hline Pós-realização & Roteiro didático & \\
\hline
\end{tabular}

A construção do vídeo considerou as atividades da Tabela 1 dentro das três etapas clássicas de produção desse tipo de material (MILLERSON, 2001): pré-produção, produção e pós-produção. Essa forma de trabalho provou ser uma maneira prática e efetiva de organização. As etapas são descritas a seguir.

\subsection{Pré-produção}

Na pré-produção foram discutidas alternativas de roteiro para ilustrar o conceito de "Momento de uma Força" em situações diferentes e corriqueiras. Para evitar algo semelhante a uma videoaula, propôs-se criar uma história sem comunicação verbal.

Duas características repercutiram sobre o formato do vídeo. A primeira foi a escolha da função de organizador prévio, que limitou o conjunto de informações a ser tratado. A segunda foi trabalhar com um vídeo curto, tanto para atender a um critério de baixa carga cognitiva (MULLER, 2008), quanto para garantir o nível de atenção dos alunos. Dessa maneira, o formato curta-metragem se mostrou mais adequado.

A adaptação de um vídeo em uma estratégia pedagógica depende da concepção de ensino empregada. Para aplicar a teoria de Ausubel, um vídeo pode ter função de organizador prévio se preparar os aprendizes com ideias âncoras relevantes antes da apresentação do material principal. Para isso, o vídeo deve seguir um roteiro que diz respeito ao assunto da aula sem fazer abordagem direta ou explícita do conteúdo, ou seja, o roteiro deve evocar conhecimento prévio que será útil na sequência. Ao fazê-lo, pode ser observada a definição e o uso de um sistema simbólico (SALOMON, 1994) ou metafórico 
(KOSCIANSKI, 2010) para representar as ideias a serem veiculadas. O argumento ${ }^{4}$ para o vídeo proposto foi:

"O curta-metragem "Momento de uma Força" apresenta a história de uma personagem em dificuldade para trocar o pneu furado de sua caminhonete. O protagonista é um senhor de cabelos brancos e franzino que, logo após retirar a caminhonete da garagem de sua casa, percebe que um dos pneus está furado. Então, retira com calma o equipamento necessário para troca do pneu, como chave de roda, macaco e pneu estepe. Surge um problema quando, mesmo com muita força e várias tentativas diferentes, não consegue afrouxar o parafuso da roda usando uma chave convencional. Em outra cena, um passarinho começa a pular nas hastes de uma antena de TV sobre o telhado. O passarinho quebra as hastes quando pula mais próximo das suas extremidades. A personagem principal observa a ação do passarinho e estende o tamanho da chave de roda encaixando nela um cano. Quando finalmente consegue retirar o parafuso, o passarinho o rouba e voa para longe, fechando o vídeo."

Na realização do roteiro decidiu-se empregar o recurso da exageração, comum nos desenhos animados clássicos. A exageração é utilizada para enfatizar os movimentos e as emoções da personagem e também pode ser usada para passar conceitos abstratos com maior ênfase (CHAMPOUX 2001). Outro ponto importante foi a elaboração do clímax, que deveria ter um impacto dramaticamente forte.

\subsection{Produção e pós-produção}

Uma vez pronta a história, teve início a tarefa de projeto de personagens (FORD e LEHMAN, 2002). Dada a relativa simplicidade do roteiro, não houve grandes questões a resolver, como definir com precisão traços psicológicos. A aparência do protagonista foi inspirada na personagem de um famoso filme de ficção científica. Definido o aspecto geral da personagem, iniciou-se a modelagem tridimensional de objetos e personagens (AVGERAKIS, 2004).

A criação de uma animação digital assemelha-se a uma filmagem tradicional. Após a modelagem e animação de movimentos, como caminhada, seguem as tomadas de cena usando câmeras virtuais dentro de um software de animação. Isso envolve posicionar e regular as câmeras em posições que são designadas comumente por termos na língua inglesa, como close-up, wide shot, mid shot (MILLERSON, 1994).

A última parte da produção é a renderização. Nesse processo, o computador gera cada quadro de animação, o que envolve recalcular as posições dos personagens, efeitos de sombra e reflexão. Dependendo do nível de detalhe desejado e da resolução empregada, um único quadro do vídeo proposto poderia ocupar tempos da ordem de um minuto em um PC típico (configuração de máquinas no mercado em 2010). Neste trabalho, lançou-se mão de tempo de processamento gratuito de redes de computadores existentes na internet, conhecidas como render farm (PATOLI et al, 2009).

Concluída a renderização, foram acrescentados os efeitos sonoros e uma trilha musical de fundo. Alguns quadros do vídeo são vistos na Figura 3. 
Figura 3: Quadros capturados do curta de animação
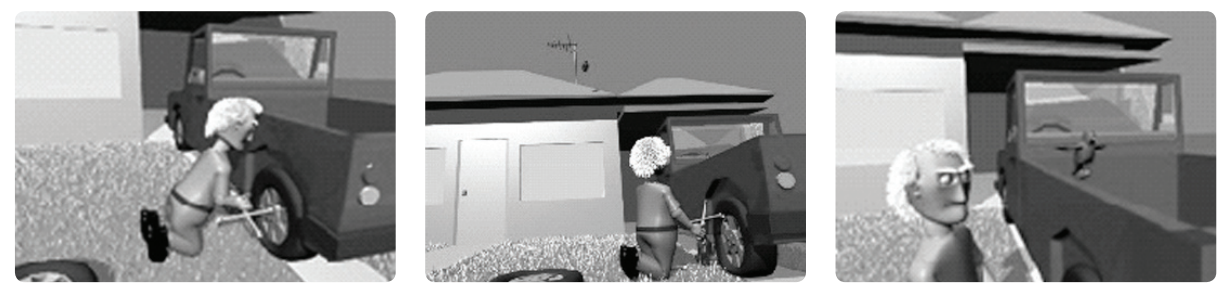

As tarefas de produção do curta de animação podem ser resumidas da seguinte forma:

1. Modelagem da personagem principal e criação de texturas.

2. Criação do esqueleto da personagem principal.

3. Modelagem do cenário e dos objetos que o compõe.

4. Modelagem da personagem secundária, o passarinho.

5. Animação das asas do passarinho.

6. Efeitos de partículas para cabelo, sobrancelhas e grama.

7. Iluminação do ambiente, configuração de reflexos e sombras.

8. Configuração das câmeras.

9. Animação das ações da personagem e dos objetos em interação.

10. Definição de movimentação das câmeras.

11. Animação da personagem secundária.

12. Renderização, totalizando 3.950 quadros.

13. Inclusão de efeitos sonoros e sincronismo com as ações.

14. Edição da trilha sonora.

15. Edição de vídeo e efeitos de transição de cenas.

Terminado o vídeo, foram adicionadas telas de título e de créditos finais, além de efeitos de vídeo ou efeitos sonoros extras. $\mathrm{O}$ vídeo foi comprimido em formato NTSC 720x480 em qualidade de DVD, com taxa de 30 quadros por segundo. Toda a produção foi realizada com o software Blender 2.48 (HESS, 2007), conjunto completo de criação 3D de licença pública GPL (FITZGERALD, 2006). O tempo total de produção foi aproximadamente 180 homens-horas, ou quarenta e cinco dias com média de quatro horas por dia.

\subsection{Pré-estreia}

Um primeiro teste da animação foi realizado com três alunos do primeiro ano e dois alunos do terceiro ano do Ensino Médio. Cada aluno recebeu, numa sexta-feira, um DVD e foi orientado a assisti-lo em casa, com a tarefa de discutir com os familiares o conceito de Física envolvido na história e escrever suas opiniões. Um dos alunos do primeiro ano, que ainda não havia tido esse conteúdo de Física, escreveu este e-mail: 
"professor, gostei bastante do vídeo, acho que consegui aprender que a força deve ser feita na ponta. Eu acho que a ideia foi passada com sucesso e também acho que mais pessoas deveriam assistir, pois é muito interessante e esses vídeos deixam a aula menos cansativa".

Nesse comentário, pode-se observar que o vídeo foi capaz de promover a principal condição para aprendizagem significativa. A ideia relevante observada no comentário é a noção prévia de "força", já existente na estrutura cognitiva. Outro aluno do terceiro ano do Ensino Médio fez o seguinte comentário:

"Assisti o vídeo e achei uma maneira muito interessante de demonstrar o conteúdo, tornando mais fácil o entendimento a partir de um recurso diferenciado [sic]. Fica claro ainda como princípios básicos da

Física podem facilitar situações cotidianas. Tem a ver com o "Princípio da Alavanca", de Arquimedes? Pesquisei aqui, hahaha! Excelente forma de explicar".

Outra vez percebe-se que o roteiro é potencialmente significativo, pois o aluno também estabeleceu uma relação com ideias relevantes - neste caso, o "Princípio da Alavanca". Além disso, o aluno se mostrou motivado a realizar espontaneamente uma pesquisa sobre o conceito presente no curta de animação.

\section{APLICAĈ̣̃O EM SALA DE AULA}

Após os testes iniciais, preparou-se a aplicação do material na sala de aula, especificamente para abordar o conteúdo de "Momento de uma Força". Foi observada a organização descrita no Quadro 1.

As etapas desse processo são descritas a seguir.

\subsection{Pré-teste}

A primeira ação do professor em sala foi aplicar as questões do pré-teste, adaptadas de Costa (1989). As cinco questões do pré-teste avaliaram o conhecimento prévio, teórico ou empírico, dos 38 alunos sobre o conceito "Momento de uma Força".

A primeira questão investigou se os alunos lembravam da aula sobre esse conteúdo de anos anteriores; apenas 10\% respondeu que sim. A segunda questão foi "Você sabe o significado do conceito 'Momento de uma Força'?", e apenas um aluno respondeu conhecer sem dúvidas.

As questões 3 e 4 do pré-teste foram retiradas da pesquisa de Costa (1989). A questão 3 ilustrou um homem com um rodo na mão e perguntou como ele poderia equilibrar o rodo na posição horizontal; houve $57 \%$ de acertos. A quarta apresentou figuras de gangorras e crianças e envolveu determinar ponto de equilíbrio, com $82 \%$ de acertos.

A quinta e última questão ilustrou um prego, uma tábua e um martelo. Havia duas situações semelhantes, com valores de posição e intensidade de forças diferentes, sendo que $71 \%$ dos alunos acertaram.

Além do registro de pré-teste, coletou-se a opinião do professor em relação ao conhecimento dos alunos. Ele lecionava para a mesma turma 
havia quatro anos e já tinha identificado um problema de ambiguidade com a palavra "momento".

\subsection{Exibição do vídeo}

Após o pré-teste, os alunos foram orientados a assistir ao curta-metragem. Durante as cenas iniciais, eles permaneceram atentos, sem significativas expressões corporais. Em um dado momento a personagem se equilibra na borda da caçamba do caminhão e cai no chão, o que provocou muitos risos e interações entre os alunos. Até o final do curta os alunos não se expressaram verbalmente; as únicas manifestações percebidas foram risadas, sons de espanto ou de surpresa e expressões corporais como resposta às ações da personagem.

\subsection{Após a exibição do vídeo}

Após a projeção, o professor passou a dirigir verbalmente e intencionalmente os comentários dos alunos.

O primeiro comentário foi de um aluno que, coincidentemente ou não, era pouco participante das aulas. Ele perguntou se a história tinha relação com o estudo das alavancas. Isso abriu um leque de opções para os demais, que passaram a citar exemplos de situações de aplicação do conceito "momento". A cada exemplo, o professor reforçou com uma explicação, salientando como o conceito se fazia presente no cotidiano. Um exemplo prático, motivado por outro comentário, foi utilizar a porta da sala de aula para uma demonstração. Um aluno foi convidado a participar e desafiado a empurrar a porta com as mãos próximo das dobradiças, enquanto o professor a mantinha aberta com um dedo.

Depois dos comentários, o conceito foi explorado no quadro de giz, com a definição de "Momento de uma Força" e desenhos pictóricos seguidos de diagramas vetoriais. Foi explicada a influência do ângulo de aplicação da força em relação ao braço de atuação no módulo da grandeza "momento". Também foi explicada a convenção de sinais para sentido horário e anti-horário. Durante a exposição foram feitas referências ao problema da personagem na animação.

Durante as interações com a turma, houve o cuidado de o professor tentar mediar a participação de todos os alunos, sabendo-se que certos comentários, ou situações como confrontos, podem dificultar uma comunicação aberta e espontânea ou bloquear totalmente alunos mais inibidos (FERRÉS 1996, p. 81).

\subsection{Pós-teste}

$\mathrm{Na}$ última parte da aula, realizou-se um pós-teste optativo, sem objetivo de avaliação formal. Todos responderam às questões.

Havia dez questões objetivas. As cinco primeiras foram questões para sondar a receptividade de se usar um curta de animação. A sexta e sétima questões verificaram se os alunos entenderam a mensagem. As três últimas trataram da grandeza "Momento de uma Força" e, por fim, um espaço para comentários livres. As respostas dos 38 alunos nas primeiras cinco questões mostraram que: 100\% 
sabia o que era um curta de animação; 100\% gostava de filmes de animação; 95\% gostou da animação feita pelo professor; $100 \%$ concordou que curtas de animação podem auxiliar o ensino de Física; e 97\% gostaria de repetir o método de ensino.

A sexta questão abordou a cena em que o passarinho pulava nas hastes da antena de TV. Todos perceberam e entenderam que pular na ponta da haste aumentava a possibilidade de quebrá-la. A sétima questão averiguou o entendimento sobre a solução usada pela personagem para afrouxar o parafuso, também com 100\% de acerto. Nas respostas às últimas questões observou-se que $95 \%$ dos alunos foram capazes de identificar em situações corriqueiras a aplicação correta do conceito "Momento de uma Força"; 92\% acertou um problema similar à quinta questão do pré-teste; e 76\% compreendeu a influência do ângulo entre o vetor força e a direção do braço na intensidade do momento.

Trinta e três alunos registraram comentários adicionais. Eles foram divididos em cinco categorias: (I) 13 alunos comentaram que a aula proporcionou melhor aprendizagem; (II) 5 alunos observaram que a aula proporcionou maior participação; (III) 7 alunos opinaram que a aula foi diferente das outras; (IV) 7 alunos destacaram a utilização da animação como recurso didático; (V) 10 alunos fizeram comentários positivos que não foram classificados nas categorias anteriores. Alguns comentários foram classificados em mais de uma categoria e nenhum teve teor negativo. Alguns deles são apresentados na Figura 4.

Figura 4: Imagens digitalizadas de comentários dos alunos.
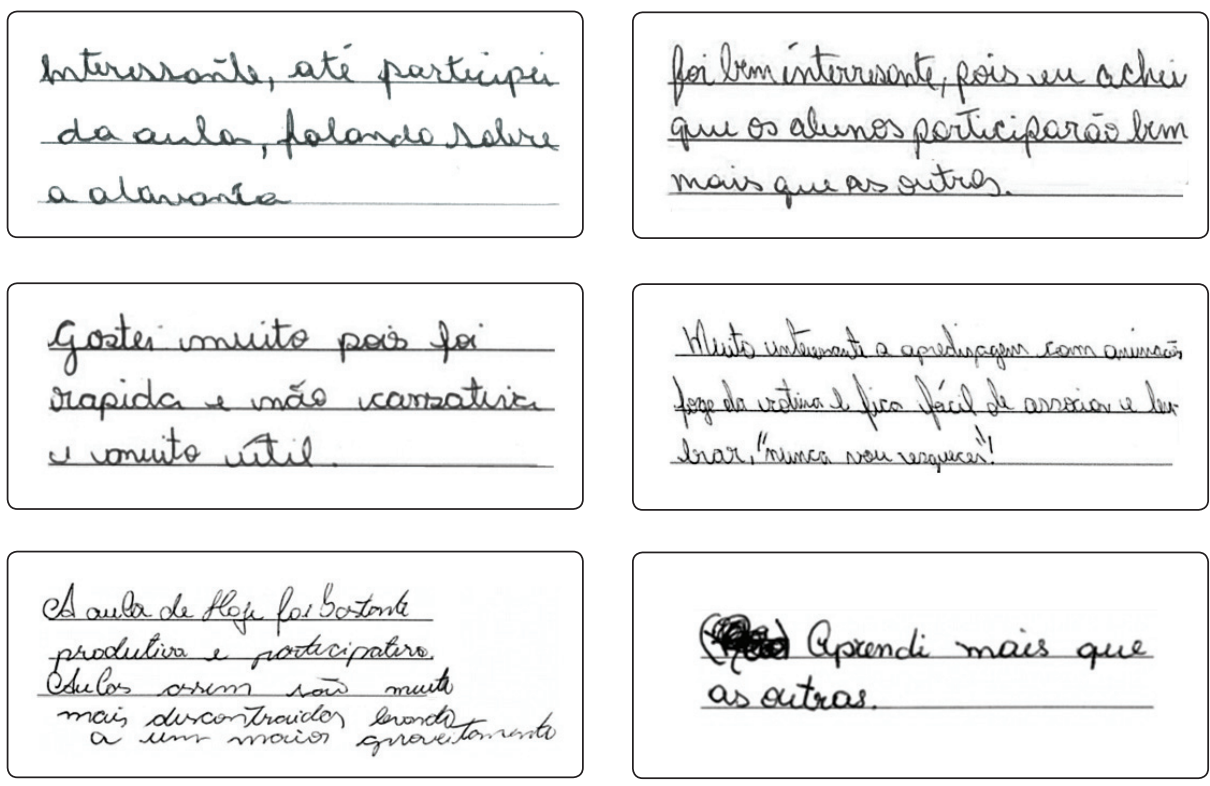


\section{DISCUSSÃO}

A análise dos resultados à luz dos critérios apontados pela literatura foi favorável no que diz respeito ao vídeo atingir o fim proposto.

As respostas das questões do pós-teste, comparadas com as do pré-teste, permitiram verificar que, em geral, os alunos assimilaram o significado correto do conteúdo "Momento de uma Força". Apenas a décima questão do pós-teste teve um menor número de acertos, $76 \%$. Muitos alunos ainda manifestaram dúvida sobre a influência que o ângulo do vetor da força aplicada tem sobre o momento. Esse fato pode motivar uma extensão do vídeo, mostrando um pássaro pousado sobre uma haste vertical e depois sobre hastes de inclinações diferentes.

As falas e os comentários dos alunos sobre a relação entre as cenas do curta e seus conhecimentos prévios mostraram que o objetivo principal de toda a preparação teórica que culminou no desenvolvimento do vídeo foi atingido, isto é: detectou-se a presença de subsunçores. Embora a aprendizagem significativa seja individualizada e dependa da estrutura cognitiva de cada indivíduo, durante a aula observou-se um resultado geral positivo. Isso foi coerente com o que se esperava do uso de estruturas cognitivas hipotéticas.

A ocorrência de aprendizagem significativa foi validada através da combinação dos mecanismos de retorno, julgando-se bastante relevantes os comentários dos alunos recolhidos no final da aula. A impressão de que a aula teria proporcionado melhor aprendizagem foi manifestada treze vezes - a categoria de comentário mais citada.

Um aspecto que também influenciou os alunos foi o fato de a animação haver sido elaborada por um de seus professores. Isso ficou evidenciado pela colaboração e pelo comportamento dos alunos no dia da aula. O curta gerou uma resposta emotiva dos alunos, bastante evidente com as gargalhadas com o tombo da personagem e a cena final em que o passarinho rouba o parafuso. Houve também um aspecto de entretenimento devido à semelhança com os clássicos dos desenhos animados. No início do planejamento, a opção pelo gênero já visava alguma diversão, mas sem correr o risco de distrair. A dosagem de diversão ou humor em uma atividade envolvendo adolescentes deve ser cautelosa, pois poderia ocorrer agitação ou euforia exagerada caso o roteiro não buscasse certa discrição.

Um risco no contexto da aula seria os alunos perceberem ou valorizarem o curta de animação apenas como um componente afetivo. Todas as observações coletadas mostraram que o valor educacional foi claramente reconhecido por eles.

Outro aspecto positivo na aplicação do curta-metragem em sala de aula é a adaptação dentro do tempo, diferente dos filmes de longa-metragem. No colégio em que se realizou o estudo, cada disciplina é apresentada em uma sessão de quarenta e cinco minutos. A animação "Momento de uma Força" tem menos de três minutos de duração, promoveu a imediata participação dos alunos e ótima participação. Essa característica de tempo também foi comentada pelos alunos.

Este trabalho propôs três elementos básicos para desenvolver roteiros de curta de animação com função de organizador prévio: 
- um mundo: que seja significativo para o aluno; e um ambiente favorável para reproduzir situações que envolvem o conteúdo a ser aprendido;

- uma personagem: que seja receptiva e curiosa na exploração do problema; e que demonstre conhecimento do assunto no mesmo nível que o aluno;

- um problema: que seja significativo e que sirva como âncora entre o que o aluno já sabe e aquilo que irá aprender. O desfecho do problema deve ser elaborado para permitir discussões entre professor e alunos após a exibição do curta.

Como resultado final, esta pesquisa apresenta uma síntese com apontamentos que reforçam a produção de curtas de animação com função de organizadores prévios, conforme observado na Tabela 3.

Tabela 3: Paralelo entre vídeos e organizadores prévios.

\begin{tabular}{|l|l|}
\hline CURTAS DE ANIMAC̣Ão & ORGANIZADORES PRÉVIOS \\
\hline Roteiros curtos e focados & Conjuntos pequenos de informações \\
\hline Envolventes e interpretativos & Preparam para o material principal \\
\hline Não são vídeo aulas & Não apresentam o conteúdo principal \\
\hline São de curta duração & São pequenos materiais introdutórios \\
\hline Linguagens de fácil entendimento & $\begin{array}{l}\text { Linguagens sem termos técnicos } \\
\text { lalunos imaturos em termos cognitivos) }\end{array}$ \\
\hline Iniciam com uma situação desestabilizadora & Iniciam com estruturas cognitivas desorganizadas \\
\hline Técnicas de antecipação ou de suspense & $\begin{array}{l}\text { Manipulação intencional de estruturas } \\
\text { cognitivas idiossincráticas }\end{array}$ \\
\hline Despertam sentimentos e emoções & \begin{tabular}{l} 
Despertam disponibilidade para aprendizagem \\
\hline
\end{tabular}
\end{tabular}

\section{CONCLUSÃO}

Atualmente, o curta "Momento de uma Força" encontra-se em meio digital em endereços eletrônicos ${ }^{5}$. Essa versão da animação possui dois minutos e quarenta e sete segundos de duração. Um vídeo mostrando imagens da construção do curta também se encontra disponível na internet ${ }^{6}$.

A criação do curta em meio digital facilita a sua utilização, pois vídeos na internet podem ser copiados em mídias portáteis para serem exibidos em salas de aula. Os vídeos digitais na internet também permitem o acesso pelos alunos, mesmo fora da escola, ampliando as possibilidades de ensino-aprendizagem.

O curta de animação apresentou características relevantes suficientes para validar sua utilização como organizador prévio. Portanto, cumpriu sua função como um mecanismo pedagógico que efetivamente auxiliou na ligação entre aquilo que o aprendiz já sabe e aquilo que precisa saber, ou seja, houve aprendizagem 
significativa. Isso foi verificado através da manifestação e disposição dos alunos ao relacionarem o novo material a ser aprendido, de forma não arbitrária e não literal, à estrutura cognitiva idiossincrática.

É preciso estar atento ao custo de produção de um vídeo. Elaborar material multimídia requer, via de regra, a participação de pessoal habilitado, como artistas gráficos. O trabalho aqui descrito configura uma exceção, em virtude da familiaridade do pesquisador no uso do software de modelagem e demais ferramentas de edição. Apesar disso, o tempo alocado na produção foi bastante extenso. Recomenda-se que o professor responsável pela concepção didática seja auxiliado por pessoal apto em desenho e animação, livrando-o, assim, de tarefas que podem ser extremamente trabalhosas e também do risco de obter um resultado visual insatisfatório.

Finalmente, a metodologia e os apontamentos desta pesquisa (RIBEIRO, 2011) podem servir como modelos gerais para experiências futuras, em que um curta de animação, feito ou não em computador, seja construído com a função de organizador prévio ou aplicado dessa maneira em aula.

\section{AGRADECIMENTO}

Os autores agradecem à Fundação Araucária do Paraná pelo suporte financeiro.

\section{NOTAS}

${ }^{1}$ Título original: The Psychology of Meaningful Verbal Learning. Editora: Grune \& Stratton, Nova Iorque, 1963.

${ }^{2}$ É importante ressalvar que neste trabalho a representação gráfica das estruturas cognitivas hipotéticas não possui relação com os Mapas Conceituais de Novak (1981).

${ }^{3}$ A ideia nova e a ideia já estabelecida não precisam necessariamente pertencer a uma mesma área de conhecimento ou disciplina.

${ }^{4} \mathrm{O}$ argumento é um resumo da história na forma de texto utilizado para verificar a viabilidade metodológica e viabilidade artística de uma obra antes da sua produção.

${ }^{5}$ http://www.youtube.com/watch?v=1jeMYJR6LJM ou http://vimeo.com/9162433.

${ }^{6}$ http://www.youtube.com/watch?v $=$ q3P2HRYoPgQ.

\section{REFERÊNCIAS}

AUSUBEL, David P. Aquisição e Retenção de Conbecimentos: Uma Perspectiva Cognitiva. $1^{\mathrm{a}}$ ed. Editora: Plátano Edições Técnicas. Lisboa, 2003. 
AUSUBEL, David P. The Psychology of Meaningful Verbal Learning. Orlando, FL: Grune \& Stratton, 1963. AVGERAKIS, George. Digital Animation Bible. Editora: McGraw-Hill, New York, 2004.

CANTOR, Jeremy; Valencia, Pepe. Inspired 3D Short Film Production. s.l. : Editora: Course Technology PTR; 1 edition., 2004.

CHAMPOUX, Joseph E. Animated Films as a Teaching Resource. Journal of Management Education, Vol. 25, No. 1, 79-100. 2001

COMPARATO, Doc. Roteiro: Arte e Técnica de Escrever para Cinema e Televisão. Editora: Nórdica, Rio de Janairo. 1983.

COSTA, Isa et al. Da pesquisa para a sala de aula: um exemplo em mecânica. Caderno Catarinense de Ensino de Física. Florianópolis, 6 (2): 105-127, ago. 1989.

FARIA, Wilson de. Aprendizagem e Planejamento de Ensino. Editora: Ática S.A. São Paulo, 1989.

FERRÉS, Joan. Vídeo e Educação. Editora: Artes Médicas, 2 ed. Porto Algre, 1996.

FITZGERALD, B., The transformation of open source software. MIS Quarterly, Vol. 30 No. 3, pp. 587-598, September 2006.

FORD, Michael; LEHMAN, Alan. Inspired 3D Character Setup. Editora: Course Thechnology PTR, $1^{\mathrm{a}}$ ed. Florence, KY. 2002.

GAZDA, R., FLEMISTER, M. G. Design and Production of Video for Instructional Multimedia: Psychological Implications and Proposed Guidelines. Journal of Visual Literacy, Vol 19, Number 1, 95-98. 1998.

HESS, R. The Essential Blender: Guide to 3D Creation with the Open Source Suite Blender. No Starch Press. San Francisco, USA. 2007.

JOYCE, Bruce R; WEIL, Marsha. Models of teacbing. 5. ed. Boston, Massachusetts: Allyn and Bacon, 1996. KOSCIANSKI, A. Changing The Rules: Injecting Content Into Computer Games. In: CIPOLLAFICARRA, Francisco V. Quality and Communicability for Interactive Hypermedia Systems: Concepts and Practices for Design. S.l: Cipolla-Ficarra, F. V. IGI Global, 2010.

MILLERSON, Gerald. Video camera techniques. Media manuals. 2. ed. Great Britain: Focal Press, 1994. MILLERSON, Gerald. Video production handbook. 3.ed. Great Britain: Focal Press, 2001.

MOREIRA, Marco Antonio. A teoria da aprendiragem significativa e sua implementação em sala de aula. Brasília: Universidade de Brasília, 2006. 186 p.

MULLER, D. A. Designing effective multimedia for physics education. 2008. Doctoral Thesis, School of Physics, University of Sydney, Australia 2008.

NOVAK, Joseph D. Uma Teoria de Educaşão. São Paulo: Pioneira, 1981.

OLIVEIRA, João Batista Araújo. Tecnologia Educacional, Teorias da Instrução. Petrópolis, RJ: Vozes Ltda, 1975.

PATOLI, M.Z. et al. An open source Grid based render farm for Blender 3D. In. Power Systems Conference and Exposition. Seattle, USA:PSCE '09 IEEE/PES, 2009.

RIBEIRO, R. J. Curta de animação como organizador prévio no ensino da Física. 2011. Dissertação (Mestrado em Ensino de Ciência e Tecnologia) - Universidade Tecnológica Federal do Paraná, Ponta Grossa, 2011.

SALOMON, G. Interaction of Media, Cognition and Learning. Lawrence Erlbaum Associates, 1994. 
